\title{
Process-based models of feeding and prey selection in larval fish
}

\author{
Øyvind Fiksen ${ }^{1, *}$, Brian R. MacKenzie ${ }^{2}$ \\ ${ }^{1}$ Department of Fisheries and Marine Biology, University of Bergen, PB 7800, 5020 Bergen, Norway \\ ${ }^{2}$ Department of Marine Ecology and Aquaculture, Danish Institute for Fisheries Research, Kavalergården 6 , \\ 2920 Charlottenlund, Denmark
}

\begin{abstract}
Feeding success is essential to larval fish survival. We present detailed mechanistic models of the foraging processes (prey encounter, approach, pursuit, and capture) in larval fish, where all parameters have explicit physical or biological meaning. The model is a unification of the processes believed to be important to prey selectivity and environmental regulation of feeding in fish. We include the sensitivity of prey to the hydrodynamic signal generated by approaching larval fish and a simple model of the potential loss of prey due to turbulence whereby prey is lost if it leaves the perceptive field during pursuit time. We parameterise the model for larval cod Gadus morhua L., a species for which data from numerous experimental and field studies are available. Model predictions are compared to observations of feeding rates under various conditions and appear to match estimated ingestion rates and prey selection in larval cod. Observed pursuit times of larvae are long and approach velocity slow enough to avoid an escape response from prey, but too short to avoid loss of prey at high turbulence levels. The pause-travel search mode is predicted to promote ingestion of larger prey than a cruising search mode. We use these models to evaluate temporal and spatial (vertical) diel feeding rates of larval cod across Georges Bank. Contrary to previous models, our model suggests that larval cod are food-limited only in deep waters along a $160 \mathrm{~km}$ transect of the bank at a prey concentration of $20 \mu \mathrm{g}$ dry wt $\mathrm{l}^{-1}$. The spatio-temporal fluctuation of turbulence (tidal cycle) and light (sun height) over the bank generates complex structure in the patterns of food intake of larval fish, with different patterns emerging for small and large larvae.
\end{abstract}

KEY WORDS: Cod · Foraging $\cdot$ Larval fish $\cdot$ Mechanistic models $\cdot$ Prey selection $\cdot$ Turbulence

Resale or republication not permitted without written consent of the publisher

\section{INTRODUCTION}

Larval fish represent a link between fisheries science, marine ecology and oceanography. Successful recruitment relies to varying degrees on the spawning stock, physical processes and small-scale predatorprey interactions. This has triggered major efforts to build models of larval growth that integrate the effects from large-scale circulation to small-scale individuallevel processes (Hinckley et al. 1996, Werner et al. 1996, 2001, Lynch et al. 2001). Our contribution to

*Email: oyvind.fiksen@ifm.uib.no these efforts is to improve the basic formulations of interactions between larval fish and their prey in terms that can be adopted in bio-physically coupled circulation models.

Predator-prey interactions are largely determined by processes such as encounter rate, approach success and capture success. Therefore, both predators and prey have evolved sophisticated structures and behaviour to enhance feeding rates and avoid being eaten by others (Kiørboe \& Visser 1999). Recently, a number of quantitative models of small-scale processes in the plankton have been developed (e.g. Viitasalo et al. 1998, Kiørboe \& Visser 1999, Caparroy et al. 2000, Visser 2001). These studies have improved our under- 
standing of the challenges faced by the plankton. Building on these studies, we develop a model of feeding processes in larval fish including the ability of prey to detect and escape from the larvae.

A number of models and experiments have addressed the functional relationship of prey size selectivity in planktivorous fish (e.g. O'Brien et al. 1976, Eggers 1977, 1982). The question has been to what extent the diet is determined by factors such as prey size, shape, colour, motion or evasive ability, and how much of the selectivity is due to optimal foraging decisions. Several comparisons of observations and models suggest that much of the prey selectivity can be explained by combining size-dependent encounter rates and capture success (e.g. O'Brien et al. 1976, Lou et al. 1996). However, such comparisons are rarely made for larval fish, which are likely to be highly dependent on prey in the right size-range. In addition, few models of prey selectivity include the escape ability of prey, at least not in mechanistic terms. Here, we combine models of visual search behaviour in larval fish (Aksnes \& Utne 1997) with small-scale models (MacKenzie et al. 1994, Caparroy et al. 2000) of predator-prey interactions in the plankton, in order to model feeding and prey selection in larval fish.

We model the larval feeding rate as a function of prey encounter rate and capture probability. The encounter rate between a visually searching planktivore fish and its prey is largely depending on light (Aksnes \& Giske 1993, Job \& Bellwood 2000), turbulence (Rothschild \& Osborn 1988) or the interactions between these (Fiksen et al. 1998), in addition to prey characteristics such as size, contrast and locomotion (Buskey et al. 1993). We include the probability of prey escape due to turbulent motions (MacKenzie et al. 1994, MacKenzie \& Kiørboe 2000) or their detection of the flow field generated by the approaching predator (Viitasalo et al. 1998, Kiørboe \& Visser 1999). Capture success is also modelled as a mechanistic process with parameters derived from experimental observations of prey escape and larval attack velocities and directions.

\section{MODELS}

\section{Prey encounter rate}

In pause-travel searchers, the prey encounter rate $e$ (prey s${ }^{-1}$ ) can be expressed as a function of prey density $N\left(\right.$ prey $\left.\mathrm{m}^{-3}\right)$, perceptive distance $r(\mathrm{~m})$, prey swimming velocity $u\left(\mathrm{~m} \mathrm{~s}^{-1}\right)$, turbulent velocity $\omega\left(\mathrm{m} \mathrm{s}^{-1}\right)$ and pause-frequency $f\left(\mathrm{~s}^{-1}\right)$ and duration $\lambda(\mathrm{s})$ (see MacKenzie \& Kiørboe 1995 for details):

$$
e=\frac{2}{3} \pi r^{3} N f+\pi r^{2} N \sqrt{\left(u^{2}+2 \omega^{2}\right)} f \lambda
$$

The terms on the right-hand side of Eq. (1) refer to the number of prey in the sphere in front of the snout of the larvae and the number of prey that is transported into this sphere while the larvae is pausing, respectively. For cruising larvae, prey encounter rate is proportional to $r^{2} v$, where $v$ is swimming speed.

Perceptive distance (here: visual range) $r$ is cubed in the encounter rate formulation, and obviously, it is an important variable for the ingestion rate. While visual range is frequently modelled simply as an increasing function of body length $L$ (e.g. Werner et al. 1996, 2001, Leising \& Franks 1999), we have included light $E_{\mathrm{b}}\left(\mu \mathrm{mol} \mathrm{m} \mathrm{m}^{-2} \mathrm{~s}^{-1}\right)$, prey size (area of prey image $A_{\mathrm{p}} \mathrm{m}^{2}$ ), prey-inherent contrast $C$ (dimensionless), and the visual sensitivity $E^{\prime}$ (dimensionless) and light satiation $K_{\mathrm{e}}\left(\mu \mathrm{mol} \mathrm{m} \mathrm{m}^{-2} \mathrm{~s}^{-1}\right)$ of the predator. These variables are essential for estimating fish feeding and prey selection in the pelagic (Fiksen et al. 1998, Fiksen \& Folkvord 1999), where light decays exponentially with depth. Turbidity of the water will impact reactive distance through changes in the light attenuation (ambient and beam) coefficient (Aksnes \& Giske 1993, Fiksen et al. in press).

Aksnes \& Giske (1993) and Aksnes \& Utne (1997) derived the following general model of visual range in fish:

$$
r^{2} \exp (c r)=E^{\prime} C A_{\mathrm{p}} \frac{E_{\mathrm{b}}}{K_{\mathrm{e}}+E_{\mathrm{b}}}
$$

where $C\left(\mathrm{~m}^{-1}\right)$ is the beam attenuation coefficient. Due to the small prey (short $r$ ) of larval fish, the expression is accurately approximated by:

$$
r \cong \sqrt{E^{\prime} C A_{\mathrm{p}} \frac{E_{\mathrm{b}}}{K_{\mathrm{e}}+E_{\mathrm{b}}}}
$$

From Eqs. (1) to (3), it is apparent that prey encounter rate (or clearance: $e / N$ ) increases sharply with turbulent velocity and prey size. However, the realised ingestion rates are lower due to postencounter processes, and we divide these into 3 distinguishable events: (1) the probability of approaching prey without being detected ('approach'); (2) the loss of prey due to turbulent motions, i.e. 'the downside of turbulence' ('pursuit') (MacKenzie \& Kiørboe 2000); and (3) size-dependent prey escape responses ('capture') (Caparroy et al. 2000). Note that (1) and (2) are connected through the duration of the pursuit (pursuit time), i.e. the time between prey detection and the final attack. If the predator approaches too fast (short pursuit time), the chances of being detected by the prey are high (Kiørboe \& Visser 1999). If the pursuit time is too long, the chances of losing the prey due to turbulent motions are high (MacKenzie et al. 1994). 


\section{Successful approach}

The 'problem of approach' for the larva is to get close enough to attack and engulf the prey without eliciting an escape response (Buskey 1994, Kiørboe \& Visser 1999). The strike distance can therefore be viewed as a trade-off between the probability of being detected by the prey and the probability of successfully engulfing the prey during the final attack. The signal that is perceived by copepod prey is the deformation rate $\left(\mathrm{s}^{-1}\right)$ of fluids (Kiørboe \& Visser 1999). The sensitivity of several planktonic organisms to these signals has been quantified experimentally (e.g. Viitasalo et al. 1998, Kiørboe et al. 1999, Titelman 2001).

Caparroy et al. (2000) modelled approach success for a cruising larval fish (herring) assuming that variability in the search velocity of the larva caused some approaches to generate deformation rates above the detection threshold of the prey. Similarly, we first calculate the velocity $V^{*}(d)\left(\mathrm{m} \mathrm{s}^{-1}\right)$ at any specific predator-prey distance $d(\mathrm{~m})$ that generates deformation rates equal to the sensitivity threshold $\Delta\left(\mathrm{s}^{-1}\right)$ of the prey, i.e.:

$$
\Delta=\frac{3 v c\left(d^{2}-c^{2}\right)}{2 d^{4}} \Leftrightarrow V^{*}(d)=\frac{\Delta 2 d^{4}}{3 c\left(d^{2}-c^{2}\right)}
$$

where $C(\mathrm{~m})$ is the radius of the head of the larva (see Kiørboe \& Visser 1999 for details of this model). This is the maximum allowable approach velocity at distance $d$, declining with fish size and as the larva closes in on the prey. The flow field generated in front of the larva also influences the realised approach velocity, as explained in Viitasalo et al. (1998), Kiørboe \& Visser (1999) and Caparroy et al. (2000).

This implies that the minimum time to pursue a prey $\left(t_{\mathrm{p}_{\text {min }}}\right)$ is the time required to move from the reactive distance $r$ to strike distance $r_{\mathrm{s}}$ when the larva approaches at the maximum velocity $V^{*}(d)$ (limited to 1 body length $[L] \mathrm{s}^{-1}$ ) at any distance $d$ from the prey:

$$
t_{\mathrm{p}_{\min }}=\int_{d=r}^{d \overline{\bar{s}}_{\mathrm{s}}} \frac{d-r_{\mathrm{s}}}{V^{*}(d)} \mathrm{d} d
$$

If the fish tries to approach at higher velocities (shorter time), the prey will detect it and escape. Generally, $t_{\mathrm{p}_{\min }}$ increases with $r$ (i.e. $A_{\mathrm{p}}, C, E^{\prime}$ or $E_{\mathrm{b}}$ ) and $C_{\text {, }}$ and decreases with $r_{\mathrm{s}}$ and $\Delta$. However, some deviations from this may occur for specific combinations of parameters, e.g. for high $\Delta$ (insensitive prey) the approach velocity is limited by swimming speed and then $t_{\mathrm{p}_{\min }}$ decreases with $C$ (or $L$ ).

\section{The 'downside of turbulence'}

High turbulent dissipation rates reduce prey capture success in larval fish (MacKenzie et al. 1994, Mac-
Kenzie \& Kiørboe 2000). MacKenzie et al. (1994) suggested a mechanistic model that could explain this process, and later Kiørboe \& Saiz (1995) refined the model by including the decline of turbulent velocity with decreasing predator-prey distance. Their model assumes that the prey is: (1) detected at a random distance less than $r_{i}(2)$ advected in a random direction due to turbulent motions; and (3) attacked if it remains within $r$ long enough for the larvae to pursue and fixate the prey. The actual procedure to calculate the probability of a successful pursuit involves the integration over all possible encounter distances and the volume in which the prey can be moved due to turbulent motions. This yields an analytical solution to the probability that the prey is advected beyond the visual range of the larva and escapes. The drawback of the model is that it is conceptually complicated and computationally demanding in individual-based models. It is also difficult to incorporate the stochastic nature of turbulence and other parameters of the model.

To directly include the stochasticity of turbulence, we employ a Monte Carlo method to pick random turbulent advection directions. We then present the results as the average of a large number of events rather than integrating over all directions as in MacKenzie et al. (1994). The simplest possible model of successful pursuit is the condition that the prey will not escape (due to turbulence) if it remains within the visual sphere of the larvae at the end of the pursuit sequence, i.e. if

$$
r>\omega t_{\mathrm{p}}
$$

where $\omega$ is the turbulent velocity at $r$ (i.e. $\omega=1.37$ $[\varepsilon r]^{1 / 3}, \varepsilon$ is the turbulent dissipation rate $\left.\left[\mathrm{m}^{2} \mathrm{~s}^{-3}\right]\right)$ and $t_{\mathrm{p}}$ is actual pursuit time. Note that if $t_{\mathrm{p}}<t_{\mathrm{p}_{\min }}$ (Eq. 5) the prey detects the predator and escapes. The model in Eq. 6 does not include the effect of reduced relative velocities at decreasing separation distances (Kiørboe \& Saiz 1995). We developed an alternative model including the relative positions of prey and larvae over the pursuit time. This was done by assuming that the larva swims (at a fixed velocity $v=r / t_{\mathrm{p}}$ ) towards the point where the prey was when it was detected, and that the prey is advected in a random direction $\theta$ $\left[0,180^{\circ}\right]$ relative to the larva. This process is axially symmetric, therefore the distance $d(t)$ between predator and prey $t_{\mathrm{p}}$ seconds after the detection is:

$$
d\left(t_{\mathrm{p}}\right)=\int_{t=0}^{t_{\mathrm{p}}} \sqrt{[a(t)+x(t)]^{2}+y(t)^{2}} \mathrm{~d} t
$$

where $a(t)=r-v t, x(t)=1.37[\varepsilon d(t)]^{1 / 3} \cos (\theta) t$, and $y(t)$ $=1.37[\varepsilon d(t)]^{1 / 3} \sin (\theta) t$. As above, the criterion for success is $r>d\left(t_{\mathrm{p}}\right)$. It appears that these models (Eqs. 6 \& 7) yield very similar results (see below). 


\section{Capture success}

The capture success of fish larvae is likely to decrease with the prey/predator size ratio (Munk 1992, Heath 1993, Caparroy et al. 2000) and the preferred prey size will increase as the larvae grow (Munk 1997). Our model of capture success is a modification of Caparroy et al. (2000), formulated in terms of predator mouth size, strike distance, prey escape direction, the variance of this escape angle, and the relative velocities of attack and escape in predator and prey (Fig. 1).

During an attack, the prey is sucked in while the larva darts forward, and we assume the volume of water engulfed can be approximated as a cylinder determined by mouth radius and the extension $\left(x^{*}\right)$ of the attack. The prey is captured if it remains within this cylinder swept by the open mouth of the larva, i.e. if the larva reach the point $x^{\prime}$ before the prey (Fig. 1), or if:

$$
\frac{r_{\mathrm{s}}+x^{\prime}}{V_{\mathrm{a}}}<\frac{m / 2}{w \sin \theta}
$$

where $r_{\mathrm{s}}$ is strike distance, $v_{\mathrm{a}}$ is larval attack velocity, $m$ is the larval mouth diameter, $W$ is the prey escape velocity and $\theta$ is the escape angle relative to the larval attack axis. We assume that the mouth of the larva is spherical, therefore the process is axially symmetrical, and can be assessed in 2 dimensions, i.e. $\theta$ takes values $\left[0,180^{\circ}\right]$. Because:

$$
x^{\prime}=w \tau \cos \theta
$$

where $\tau$ is the time the prey needs to reach the border of the cylinder engulfed by the larva (Fig. 1):

$$
\tau=\frac{m}{2 w \sin \theta}
$$

the criterion for successful capture (Eq. 8) becomes:

$$
\frac{W}{V_{a}}\left(r_{S} \sin \theta+\frac{1}{2} m \cos \theta\right)<\frac{m}{2}
$$

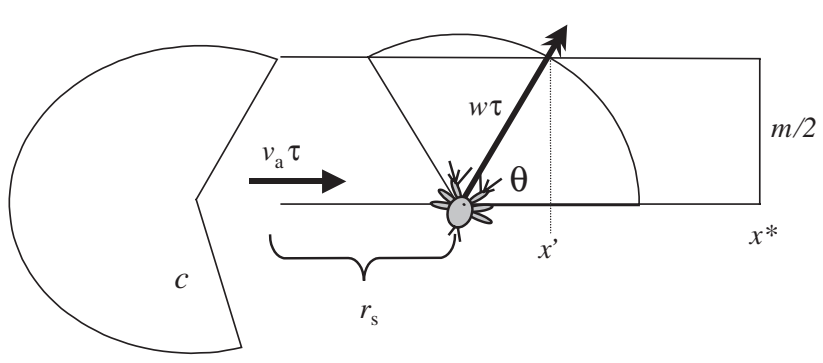

Fig. 1. A schematic drawing of a larva attacking a nauplius. Parameters are: the strike distance $r_{s}$ attack velocity $v_{a}$, head radius $c$, jump angle $\theta$, escape velocity $w$, mouth diameter $m$, time needed to get out of the engulfed volume $\tau$, boundary of the engulfed volume or maximal escape distance of the prey $x^{*}$, and the point which the larva must reach before the prey to capture it $x^{\prime}$. The jump angle is treated as a stochastic normal deviate with mean (SD) $30^{\circ}\left( \pm 30^{\circ}\right)$
We limit the extension of an attack to $L / 2$, such that prey escape if they reach $x^{*}$ without being captured (Fig. 1). In this case, they remain in front of the larva, and the attack is repeated. Prey escape jumps are approximately 3 to 5 body lengths (Viitasalo et al. 2001), but occasionally much longer, and this could also be used to constrain $x^{*}$. The capture success does not change much for values of $x^{*}$ above $\sim 0.3 L$.

The escape direction $\theta$ of the prey is not likely to be completely random because copepods are able to orient escape jumps depending on the signal from the predator (Titelman 2001). The best escape direction is near perpendicular to the attack direction of the predator. However, recognising the variance in $\theta$ and that the prey rarely escapes into the gape of the predator, random values of $\theta$ from a normal distribution with mean $30^{\circ} \pm 30^{\circ}$ (1 SD) appear reasonable from observations of variability in jump angles of nauplii (Titelman 2001).

\section{Parameterisation for larval cod}

\section{Encounter}

In larval cod, the pause frequency $f$ and pause duration $\lambda$ in Eq. (1) have previously been estimated as $0.43 \mathrm{~s}^{-1}$ and $2 \mathrm{~s}$, respectively (MacKenzie \& Kiørboe 1995). This allows about $15 \%$ of the time to be spent on swimming (Munk 1995). Two more species-specific parameters need to be estimated to parameterise visual range (Eqs. 1 to 3): first, the eye sensitivity parameter $E^{\prime}$; and second, the half-saturation parameter $K_{e}$ which defines the efficiency of the transformation of photon-flux on the retina to neural response (see Aksnes \& Utne 1997 for details on these parameters). To parameterise $E^{\prime}$ for cod larvae we compiled some published estimates of reactive distance in cod larvae where both prey and larval size are provided (Fig. 2). By rearranging Eq. (3):

$$
E^{\prime}=\frac{r^{2}}{C A_{\mathrm{p}} \frac{E_{\mathrm{b}}}{K_{\mathrm{e}}+E_{\mathrm{b}}}} \cong \frac{r^{2}}{C A_{\mathrm{p}}}
$$

and inserting values for prey contrast $C(0.3$; UtnePalm 1999) and prey image area $A_{\mathrm{p}}\left(\pi\left[0.5 \times l_{\mathrm{pi}}\right]^{2}\right.$ for spherical prey and $0.75 \times l_{\mathrm{p} i} \times d_{\mathrm{p} i}$ for elongate prey, where $l_{\mathrm{p} i}$ and $d_{\mathrm{p} i}$ are prey length and width of prey $i_{\text {, }}$ respectively), the sensitivity parameter can be found as a function of larval length and prey size (Fig. 2). This is valid if light is not limiting for visual range $\left(E_{\mathrm{b}} \gg K_{\mathrm{e}}\right)$ in the experiment. The data are scattered; for example, the measurements by Hunt von Herbing \& Gallager (2000) suggest that cod larvae have very sensitive eyes and are able to detect the protozoan Balanion sp. 


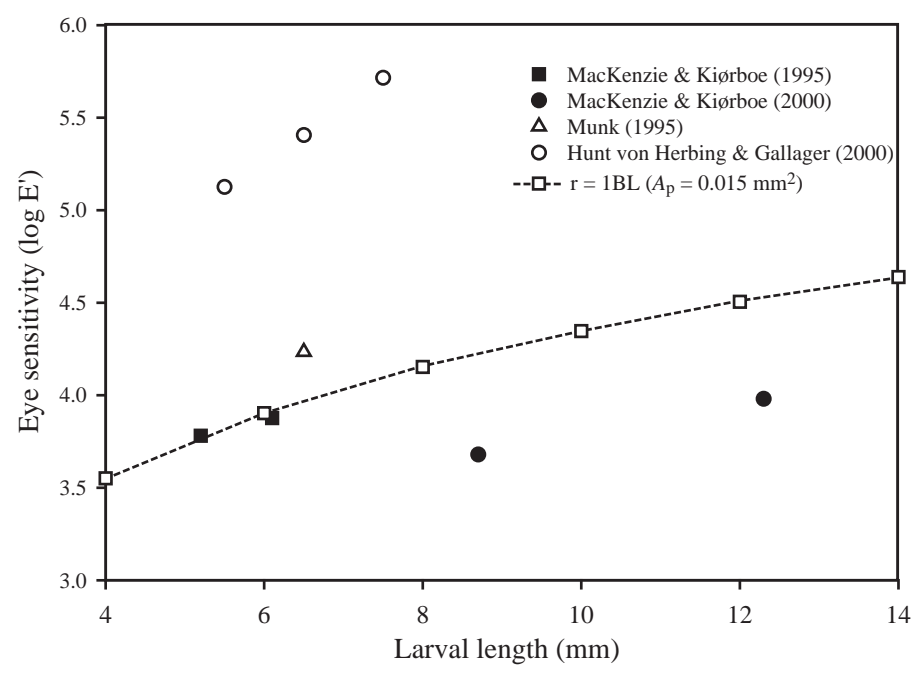

Fig. 2. Eye-sensitivity parameter $E^{\prime}$ estimated from available measures of reactive distance in cod larvae at different body lengths using Eq. (12) and inserting values of prey size, reaction distance and prey contrast for each study. Line indicates the eye-sensitivity required to discover a prey with image area $A_{\mathrm{p}}=0.015 \mathrm{~mm}^{2}$ that is a distance $L$ away under lightsatiated conditions

(0.05 mm body length) at a distance of $>1$ fish body length $L$. This corresponds to detecting a spherical prey with diameter $0.1 \mathrm{~mm}$ more than $3 L$ away, which is high compared to other measures of visual capability or acuity reported in the literature. Balanion sp. swims continuously at high velocities and this may have affected the reactive distance by making it more conspicuous to cod larvae (Buskey et al. 1993, Utne-Palm 1999).

We have made the (conservative) assumption that exogenously feeding cod larvae will be able to detect a $0.2 \times 0.1 \mathrm{~mm}$ prey $1 L$ away under optimal light conditions, which is within the range typically reported from observations (MacKenzie \& Kiørboe 1995, 2000, Munk 1995, Rasmussen 1999). All data in Fig. 2 are observed reactive distances, which must necessarily be shorter than maximum visual range.

The only species for which the light-satiation parameter $K_{\mathrm{e}}$ has been measured explicitly is the 2-spotted goby Gobiusculus flavescens (Aksnes \& Utne 1997, $K_{\mathrm{e}}=5.0 \mu \mathrm{mol} \mathrm{m} \mathrm{m}^{-2} \mathrm{~s}^{-1}$ ). In bluegill Lepomis macrochirus and white crappie Pomoxis annularis $K_{\mathrm{e}}$ is between 0.05 and $0.1 \mu \mathrm{mol} \mathrm{m}{ }^{-2} \mathrm{~s}^{-1}$ (O'Brien 1987). For larval cod, some experiments (Ellertsen et al. 1980, Huse 1994) suggest that feeding is severely light limited below 1.9 to $7.8 \times 10^{-3} \mu \mathrm{mol} \mathrm{m} \mathrm{m}^{-2} \mathrm{~s}^{-1}$. These studies used the frequency of larvae with prey in their guts ('feeding incidence') at different light intensities as an indicator of feeding. The prey concentrations in these and other (Puvanendran \& Brown 1998, van der Meeren
\& Jørstad 2001) investigations on the effect of light on growth and survival in larval cod were very high (50 to $4000 \mathrm{l}^{-1}$ ) compared to natural conditions. This may have caused the larvae to feed non-visually, and to reach satiation at artificially low light levels, even if visual range was reduced considerably. Instead of a feeding threshold (Blaxter 1986, Ellertsen et al. 1980), we contend that light will act gradually on the ingestion rate of cod larvae. However, it is difficult to define the exact level of $K_{\mathrm{e}}$ from available data. It is likely that $K_{\mathrm{e}}$ in $G$. flavescens is quite high, as this species lives in the littoral zone and is therefore adapted to high levels of irradiance. Cod larvae are adapted to lower light levels, but the lowest values of roughly $0.005 \mu \mathrm{mol} \mathrm{m} \mathrm{m}^{-2}$ $\mathrm{s}^{-1}$ (Huse 1994) appear to be very low and we have used the intermediate value of $1 \mu \mathrm{mol} \mathrm{m} \mathrm{m}^{-2} \mathrm{~s}^{-1}$ in the model. This parameter will affect feeding rates only when light is limiting, and may vary between stocks experiencing different light intensities during early life (Puvanendran \& Brown 1998). It is also likely to improve as the eye develops ontogenetically (Fiksen et al. 1998, Job \& Bellwood 2000).

\section{Approach}

Our formulation of the approach success (Eqs. 4 \& 5) permits direct use of actual pursuit times estimated for larval cod in turbulent water (MacKenzie \& Kiørboe 2000). We separated these estimated pursuit times into 6 turbulent velocity groups containing the same number of observations $(6 \times 11)$, and then, depending on the actual $\omega$, we drew $t_{\mathrm{p}}$ values randomly (by Monte Carlo methods) from the corresponding turbulence category. If the random pursuit time $t_{\mathrm{p}}$ from these values is less than $t_{\mathrm{p}_{\min }}$ then the predator must exceed $v^{*}$ at some point during the pursuit and the prey is alerted and escapes.

Larger Acartia tonsa are more sensitive to fluid deformation (Kiørboe et al. 1999), and the larvae therefore have longer $t_{\mathrm{p}_{\min }}$ for larger prey (Fig. 3). The modelled approach success declines substantially over the prey/predator length interval of 5 to $9 \%$ (Fig. 3), using the deformation thresholds estimated for $A$. tonsa (Kiørboe et al. 1999) and the pursuit times estimated by MacKenzie \& Kiørboe (2000). We see that the observed pursuit times $\left(t_{\mathrm{p}}\right)$ are nearly always longer than $t_{\mathrm{p}_{\min }}$ (Fig. 3); only when turbulent velocities are high does $t_{\mathrm{p}}$ approach $t_{\mathrm{p}_{\min }}$

Pursuit

The measurements of both relative velocities (turbulence) and pursuit times in larval cod reveal con- 


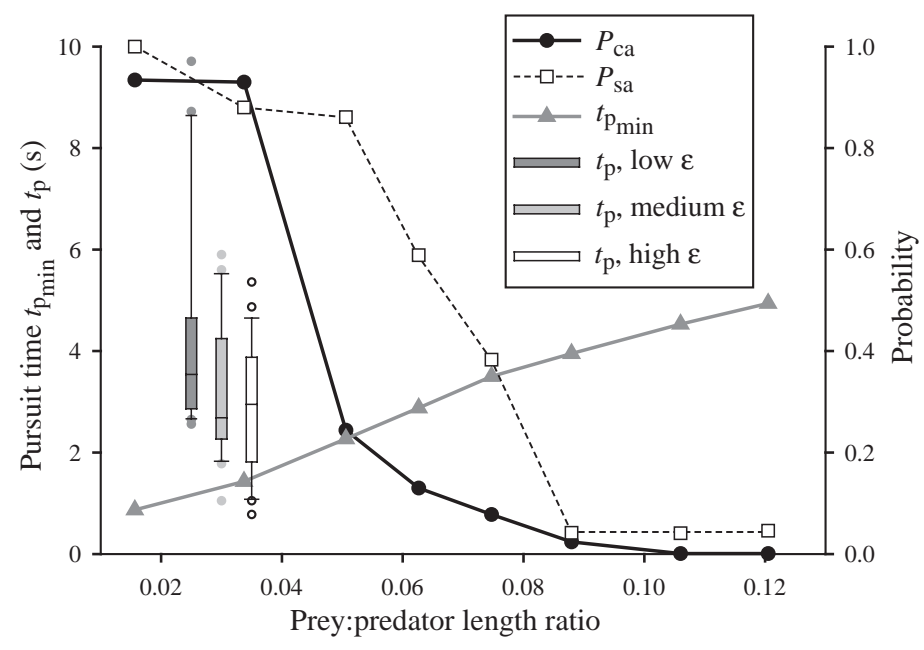

Fig. 3. Minimum pursuit time $\left(t_{\mathrm{p}_{\min }}\right)$, the probability of approaching without being detected $\left(P_{\mathrm{sa}}\right)$ and the capture success $\left(P_{\text {ca }}\right)$ for various prey/predator ratios ( $8 \mathrm{~mm}$ larva). We set the threshold deformation rate of the prey $\Delta=0.0264 /$ prey length, as estimated by Kiørboe et al. (1999) for Acartia tonsa. The average size-dependent capture success (see Fig. 1) is plotted for $V_{a}=10 L, W=100 \operatorname{lp}, \ln (m)=-3.27+1.82 \ln L-$ $0.12(\ln L)^{2}$ (A. Folkvord pers. com.), $x^{*}=0.5 L$ and $\theta=30^{\circ} \pm 30^{\circ}$ (normal deviate). $P_{\mathrm{sa}}$ is the realised approach success with $t_{\mathrm{p}}$ drawn from the observations by MacKenzie \& Kiørboe (2000) (with $\varepsilon=0.1 \mathrm{~mm}^{2} \mathrm{~s}^{-3}$ ). These observations are included as Box-Whisker plots (boxes show the 25th and 75th percentile, whiskers show the 10th and the 90th percentile, and the dots are points outside this range) at low, medium and high turbulent velocities (all measured at a prey:predator length ratio of $3 \%$ )

siderable variability both within and among treatments (MacKenzie \& Kiørboe 2000) reflecting the stochastic nature of both turbulence $(\omega)$ and larval behaviour $\left(t_{\mathrm{p}}\right)$. We explored different ways to implement stochasticity in the values of pursuit time and dissipation rate estimated by MacKenzie \& Kiørboe (2000) within the alternative models of pursuit success (Eqs. 6 \& 7).

First, since the data on actual pursuit times $t_{\mathrm{p}}$ from MacKenzie \& Kiørboe (2000) correspond well to a lognormal distribution (mean $\ln \left(t_{\mathrm{p}}\right)=1.14 \pm 0.48, \mathrm{n}=66$ ), random pursuit times were drawn from:

$$
t_{\mathrm{p}}=\mathrm{e}^{1.14+0.48 N(0,1)}
$$

where $N(0,1)$ is a standard normal deviate. The resulting pursuit success with increasing deterministic turbulence is shown as Mod1 in Fig. 4. The model with reduced relative velocities (Eq. 7) during the approach did not affect the predictions from the model (Mod2, Fig. 4). This was true even if the changes in $\omega$ were reformulated to account for changes above and below the Kolmogorov scale (Kiørboe \& Saiz 1995). This simple version is quite similar to the original model from MacKenzie et al. (1994).
Second, the data on pursuit success at each level of turbulence (MacKenzie \& Kiørboe 2000) were averaged over a number of encounter events, and the variability in $\varepsilon$ at each point can be included by drawing random values of $\omega$ from a log-normal distribution, e.g.:

$$
\omega=1.37(\varepsilon r)^{1 / 3} e^{N(0,1)}
$$

Using this variance structure, the probability of successful pursuits versus the averaged (realised) turbulence velocities show a very accurate fit with the data (Mod3, Fig. 4). Third, the turbulence velocities were drawn from a normal distribution with mean $\omega$ and standard deviation $\omega / 2$ (Mod4, Fig. 4). Furthermore, splitting the observed $t_{\mathrm{p}}$ values (MacKenzie \& Kiørboe 2000) into only 3 categories (as in Fig. 3) before randomisation did not affect the predictions significantly. Nor did stochastic variance of reactive distance (around the visual range) influence the results. In general, more stochastic variance on parameters and $\omega$ will tend to flatten the probability function, while the deterministic version of the model is a 0 or 1 solution, switching near the inflection point of the curve. All of the proposed models accounted for the variance in the data quite well (Fig. 4), and rather arbitrarily, we applied Mod4 as our default model for the remaining calculations. For each encounter event, the same stochastic value of $t_{\mathrm{p}}$ is used to calculate the approach success and pursuit success at each encounter event.

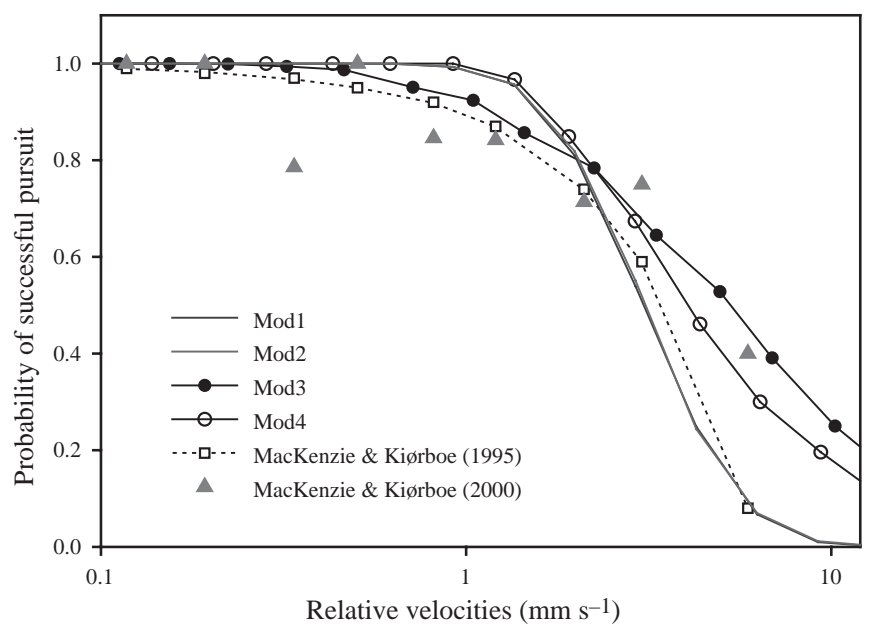

Fig 4. Observed average capture success (filled triangles), the original model (from MacKenzie et al. 1994, Kiørboe \& Saiz 1995), and the new, simple model with (Mod1, Eq. 7) and without (Mod2, Eq. 6) the decreasing relative velocities at decreasing separation distances (the models are indistinguishable). The third model (Mod3) also includes a log-normal distribution of $\omega$ in the capture success iteration (Eq. 14) versus the average $\omega$ from all iterations. In Mod4, the pursuit times are drawn from the observed values directly, while $\omega$ is drawn from a normal distribution withvariance $\sqrt{w / 2}$ 
Overall, the simple model (Eq. 6) yields surprisingly similar results compared to the original, more complicated version, and is in range with the data. Note that the present model applies the pursuit time data in a different way than was done by MacKenzie \& Kiørboe (2000). They used the intercept of the regression line of $t_{\mathrm{p}}$ over $\ln (\omega)$ as an estimate of $t_{\mathrm{p}}$ in calm water, which was then used as a constant when determining probability of successful pursuit. The data were less well explained when they included the decline in $t_{\mathrm{p}}$ with turbulence (their Fig. 7). Here, we consistently use pursuit times that are dependent on turbulent velocity.

The model predictions and observations suggests that, in turbulent water, advective loss of the prey from within the visual range is the main factor affecting pursuit success (Fig. 4), rather than prey escape caused by detection of the approaching predator by the prey (Fig. 3). Expressed alternatively, the predator usually approached its prey sufficiently slowly to avoid detection, but at the risk of losing its prey due to turbulence. For example, over a wide range of turbulent velocities, $t_{\mathrm{p}}$ was always above $t_{\mathrm{p}_{\min }}$ (Fig. 3). Only at the highest turbulent velocities was the approach of the larvae fast enough (in some instances) to stimulate prey escapes. This suggests that if larvae adapt their pursuit behaviour to rapidly advecting prey in highly turbulent environments (e.g. by approaching faster) they will be detected by the prey. Hence, in such environments, pursuits can be unsuccessful because: (1) larvae are too slow to approach the prey before it is lost from view; (2) their faster approach velocities (required to maintain prey in view) elicit prey escapes; or (3) a combination of these 2 processes results in failed pursuit. In low to moderate turbulence (where $t_{\mathrm{p}}>t_{\mathrm{p}_{\text {min }}}$ Fig. 3), larvae can increase their approach velocity to follow advecting prey without eliciting prey escapes. This behaviour allows successful approach and pursuit as the environment changes.

We note that the amount by which larvae can increase their approach velocity to maintain the prey in view will be constrained by species-specific differences in prey sensitivity to fluid deformation (Titelman 2001). Consequently, this interaction could be a factor which influences the species composition of prey diets in different turbulence settings (Dower et al. 1998, Hillgruber \& Kloppmann 2000). On the other hand, it has been suggested that zooplankton adapt to higher turbulence levels by increasing their sensitivity threshold to hydromechanical signals (e.g. Kiørboe \& Saiz 1995, Visser 2001). This is not included in the model, but could potentially allow the larva to increase its approach velocity or reduce its strike distance at higher turbulence levels without generating an escape response. Generally, a higher sensitivity threshold will shift $t_{\mathrm{p}_{\min }}$ downwards (Fig. 3) allowing shorter $t_{\mathrm{p}}$.
To quantify the importance of adjusting the pursuit duration, we calculated the probabilities of successful approach $\left(P_{\mathrm{sa}}\right)$ and pursuit $\left(P_{\mathrm{sp}}\right)$ for 6 and $10 \mathrm{~mm}$ larvae under different turbulent conditions assuming either fixed short or long $t_{\mathrm{p}}$, or pursuit times that vary with turbulence (Table 1). The cost of using the long (calm water) $t_{\mathrm{p}}$ at high turbulent velocities is to reduce pursuit success by between 50 and $150 \%$, depending on larval size and turbulence. The benefit is to increase $P_{\text {sa }}$ by about 20 to $30 \%$ in turbulent situations, i.e. the costs outweigh the benefits. Correspondingly, reversing the behaviour and using short $t_{\mathrm{p}}$ in all environments would reduce $P_{\text {sa }}$ by 20 to $30 \%$ in calm situations, but have no effect on $P_{\mathrm{sp}}$ at high turbulence. In all cases except one (medium turbulence, large larva) the flexible strategy is beneficial.

The probability of successful approach decreases with larval size (Table 1), even though the relative prey:predator size-ratio remains the same. This is caused by the increasing deformation rate sensitivity (lower $\Delta$ ) and the increasing larval cross section size (c) as both larvae and their prey increase in size. Additionally, larger larvae are generally less sensitive to the 'downside of turbulence' $\left(P_{\mathrm{sp}}\right.$, Table 1$)$ because their visual range is longer.

\section{Capture}

The attack velocity $v_{a}$ is difficult to measure, but Hunt von Herbing et al. (2001) estimated it to be 2 to $3 \mathrm{BL} \mathrm{s}^{-1}$ in larval cod. Bailey \& Batty (1984) found burst speed in larval cod to be about 10 to 14 body lengths $\mathrm{s}^{-1}$, and other species ranging from 10 to 20 body lengths $\mathrm{s}^{-1}$. The escape speed of copepods is typically

Table 1. Probabilities of successful approach $\left(P_{\mathrm{sa}}\right)$ and successful pursuit $\left(P_{\mathrm{sp}}\right)$ under different assumptions of the duration of pursuit time. The alternatives are to use fixed short $t_{\mathrm{p}}$ (high turbulence), long $t_{\mathrm{p}}$ (calm water) or the flexible (default) behaviour registered by MacKenzie \& Kiørboe (2000). Probabilities are modelled for small $(6 \mathrm{~mm})$ and large $(10 \mathrm{~mm})$ larvae under calm, medium and turbulent conditions $(0,1$ and $10 \mathrm{~mm}^{2} \mathrm{~s}^{-3}$ ). Prey:predator size ratio is $5 \%$. Bold numbers are the alternative with maximal ingestion success

\begin{tabular}{|c|c|c|c|c|c|c|c|}
\hline \multirow{3}{*}{$\begin{array}{l}\text { Larval } \\
\text { size } \\
(\mathrm{mm})\end{array}$} & \multirow{3}{*}{$\begin{array}{c}\text { Behaviour } \\
\left(t_{\mathrm{p}}\right)\end{array}$} & \multicolumn{6}{|c|}{ Level of turbulence } \\
\hline & & \multicolumn{2}{|c|}{$0 \mathrm{~mm}^{2} \mathrm{~s}^{-3}$} & \multicolumn{2}{|c|}{$1 \mathrm{~mm}^{2} \mathrm{~s}^{-3}$} & \multicolumn{2}{|c|}{$10 \mathrm{~mm}^{2} \mathrm{~s}^{-3}$} \\
\hline & & $P_{\mathrm{sa}}$ & $P_{\mathrm{sp}}$ & $P_{\mathrm{sa}}$ & $P_{\mathrm{sp}}$ & $P_{\mathrm{sa}}$ & $P_{\mathrm{sp}}$ \\
\hline \multirow[t]{3}{*}{6} & Short & 0.83 & 1 & 0.83 & 0.59 & 0.83 & 0.27 \\
\hline & Flexible & 1 & 1 & 0.83 & 0.59 & 0.83 & 0.27 \\
\hline & Long & 1 & 1 & 1 & 0.32 & 1 & 0.11 \\
\hline \multirow[t]{3}{*}{10} & Short & 0.69 & 1 & 0.69 & 0.86 & 0.69 & 0.45 \\
\hline & Flexible & 1 & 1 & 0.69 & 0.86 & 0.69 & 0.45 \\
\hline & Long & 1 & 1 & 1 & 0.64 & 1 & 0.21 \\
\hline
\end{tabular}


reported to range from $\sim 20$ to 200 body lengths $\mathrm{s}^{-1}$ depending on species (Mauchline 1998, Viitasalo et al. 1998, 2001, Rasmussen 1999, Titelman 2001). In this model, it is the ratio of escape to attack velocities $\left(w / v_{a}\right)$ that matters (Eq. 11), and our default value of this ratio is $10 l_{\mathrm{pi}} / L$. The larval attack velocity also includes the suction velocity component (potentially as much as 45 body lengths $\mathrm{s}^{-1}$; Drost 1987) and any delay in the escape response of the prey.

From our model, the optimal strike distance $r_{\mathrm{s}}$ can be viewed as a trade-off between the probabilities of successful approach $\left(P_{\mathrm{sa}}\right)$ and capture $\left(P_{\mathrm{ca}}\right)($ Fig. 5). Strike distance has been reported to be 5,7 and $16 \%$ of body length in juvenile sticklebacks (Viitasalo et al. 1998), larval anchovy (Hunter 1972) and cod (MacKenzie \& Kiørboe 2000), respectively, and varies with prey size, at least for cod larvae preying on Acartia tonsa nauplii and copepodites (Rasmussen 1999). Reducing $r_{\mathrm{s}}$ implies reduced approach velocities (Eq. 4, lower $P_{\mathrm{sa}}$ ) and longer minimum pursuit times (Eq. 5, higher $P_{\mathrm{ca}}$ ). For the prey:larval length ratio of $3 \%$ used in the experiment by MacKenzie \& Kiørboe (2000), $P_{\mathrm{sa}}=1$ for $r_{\mathrm{s}}>\sim 0.02 L$, while $P_{\text {ca }}$ declines rapidly for $r_{\mathrm{s}}>\sim 0.18 L$,
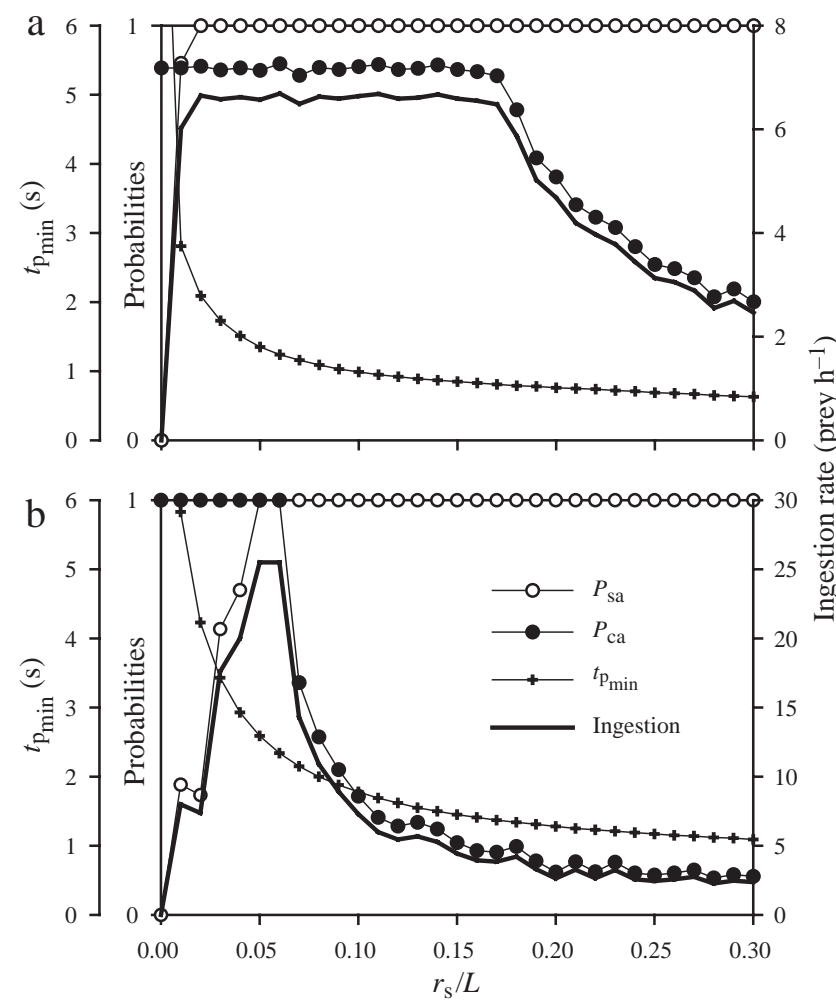

Fig. 5. Probability of successful approach $\left(P_{\mathrm{sa}}\right)$ and capture $\left(P_{\mathrm{ca}}\right)$, minimum pursuit time $\left(t_{\mathrm{p}_{\min }}\right)$ and ingestion rates for increasing strike distance $r_{\mathrm{s}}$ in calm water. (a) Predator-prey size ratio $\left(l_{\mathrm{p}} / L\right)=0.03$ (same predator-prey size ratio as in the experiment by MacKenzie \& Kiørboe 2000) and (b) $l p / L=0.07$ (large prey) i.e. the optimal strike distance is in the range 2 to $18 \%$ of body length (Fig. 5a), within which lies the value reported by MacKenzie \& Kiørboe (2000). For larger prey, however, the predicted optimal strike distance is shorter, and approximately $5 \%$ of $L$ for a prey:predator length ratio of 6 to $7 \%$ (Fig. 5b). In fact, a strike distance near 5 to $10 \%$ of $L$ appears to yield near maximum ingestion rates for all prey sizes, and our default value of $r_{S}$ is therefore $0.1 L$.

With these parameters, the capture success will drop from high to low in the prey:predator size-range of 4 to $8 \%$ (Fig 3). This means that capture success has primacy over approach success in shaping the ingested size-spectra, at least for the prey deformation rate sensitivity used here. Since Acartia tonsa is among the most sensitive copepods (Titelman 2001), this is likely to hold generally.

\section{Comparisons with observations from laboratory, field and other models}

\author{
Clearance and ingestion rates compared \\ to experiments
}

Munk (1995) estimated the maximum values of clearance rate $(e / N)$ in larval cod to be $81 \mathrm{~cm}^{3} \mathrm{~min}^{-1}$ at low prey concentrations, i.e. when larval search activity was at a maximum. Additionally, he found that the consumption rate of hungry cod larvae was on average 0.26 prey $\mathrm{min}^{-1}$ (based on stomach contents), and the capture success was about $22 \%$. If we model this situation $\left(N=14 \mathrm{l}^{-1}, E_{\mathrm{b}}=23 \mu \mathrm{mol} \mathrm{m} \mathrm{m}^{-2} \mathrm{~s}^{-1}, l_{\mathrm{p}}=0.23, d_{\mathrm{p}}=\right.$ $0.12, L=6.1 \mathrm{~mm}$ and $\varepsilon=0$ ), we obtain a clearance rate of about $20 \mathrm{~cm}^{3} \mathrm{~min}^{-1}$ and a capture probability of $91 \%$. The predicted ingestion rate is in fact exactly 0.26 prey $\mathrm{min}^{-1}$. The experiments performed by Munk (1995) were however conducted in turbulent water of unquantified intensity. If the turbulent dissipation rate in our model is increased from 0 to 0.1 and $10 \mathrm{~mm}^{2} \mathrm{~s}^{-3}$ (corresponding approximately to the turbulence generated at $20 \mathrm{~m}$ depth by wind speeds of 7 and $32 \mathrm{~m} \mathrm{~s}^{-1}$; MacKenzie \& Kiørboe 2000), the modelled clearance rate increases to 32 and $48 \mathrm{~cm}^{3} \mathrm{~min}^{-1}$, respectively. The ingestion rate is 0.34 prey $\mathrm{min}^{-1}$ at intermediate turbulence and drops to 0.30 prey $\mathrm{min}^{-1}$ at strong turbulence. The corresponding capture successes are 0.74 and 0.45 . Thus, the model yields values for capture success which are too high and clearance rates which are too low compared with the observations, although the total ingestion rate is similar. The same exercise for the experiment by MacKenzie \& Kiørboe (1995) also gave reasonable agreement between observed and predicted values for prey densities of $<50 \mathrm{l}^{-1}$. 


\section{Prey selection}

Given equal concentrations, larger prey will be encountered more frequently (longer, $r$ ) than small prey, while smaller prey are easier to catch than larger prey. The combined effects of these size-dependent processes are that the larvae will consume relatively more prey of some size-categories than of others. This can be illustrated in terms of Chesson's preference index (e.g. Munk 1997):

$$
P_{i}=\frac{\alpha_{i} / n_{i}}{\sum_{j=1}^{j=J} \alpha_{j} / n_{j}}
$$

where $\alpha_{i}$ and $n_{i}$ are the number of prey type $i$ eaten and in the environment, respectively, and $J$ is the number of prey types considered. To illustrate these effects, we generated a prey population containing a range of sizes to which we exposed a larval fish predator in calm water. We then calculated its simulated 'preference', given the constraints imposed by larval foraging behaviour (e.g. visual range, pursuit time) and prey escape behaviour (e.g. fluid deformation detection thresholds, escape velocities).

The Chesson preference spectrum peaks at a $l_{\mathrm{p}} / L$ size ratio of about $5 \%$ for all larval cod sizes, which is near the optimal size ratio observed by Munk (1997) in the North Sea (Fig. 6). This ratio was remarkably stable with size for larval cod captured at sea under natural turbulence conditions (Munk 1997). No prey below $2 \%$ and above 7 to $10 \%$ of larval size was found in the natural diet (Munk 1997), and this is near the minimum

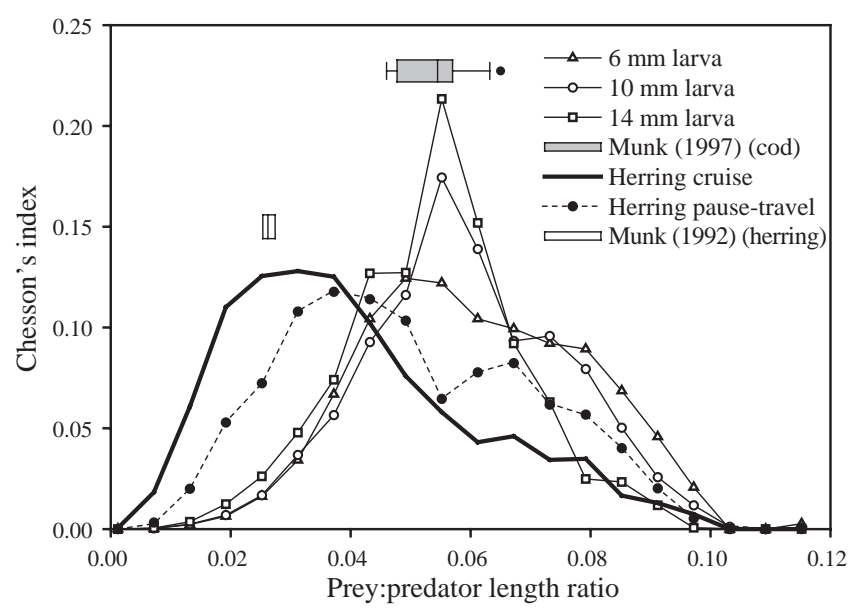

Fig. 6. Chesson's index for larval cod of 6, 10 and $14 \mathrm{~mm}$ length (dotted lines) offered the same distribution of prey $\left(r_{\mathrm{s}}=\right.$ $0.1 \mathrm{~L}$ ) including encounter, approach, pursuit and capture success. Solid lines are larval herring $(m=0.0382 L-0.0147$; Heath 1993) using either a cruising (fat line) or pause-travel (thin line) search strategy. Box-Whisker plots are estimates of the prey:larval lengths where Chesson's index peaks for herring (Munk 1992) or cod (Munk 1997) larvae and maximum prey size eaten by the modelled cod. To assess the generality of the model to other species, we did a simulation of prey selection in larval herring. Herring and cod larvae are quite dissimilar in their morphology; herring are longer, have a smaller mouth and adopt a cruising search behaviour (MacKenzie \& Kiørboe 1995). With these changes, the model predicted the optimum prey size of herring quite well (Fig. 6). However, the model suggests a long tail towards larger prey sizes that was not visible in the data (Munk 1992).

The cruising search mode of larval herring decreases the preferred prey size relative to the pause-travel mode (Fig. 6). With pause-travel search behaviour the larva scans a 3-dimensional sphere, and then swims to scan a new sphere (Eq. 1), while a cruising predator scans a 2-diminsional area as it swims forward. Therefore, the encounter rate in pause-travel searchers are cubed with visual range $r$, but only squared with $r$ for cruising predators. This difference increases the encounter of large relative to small prey in pausetravel compared to cruising larvae.

Ingestion rates across a transect at Georges Bank

We placed larval fish in various depths across a section of Georges Bank, and calculated the specific ingestion rate of the larvae over $24 \mathrm{~h}$ (Fig. 7). The model was forced with irradiance at the surface and the tide- and wind-generated variations in turbulence (dissipation rates) over the bank. We used the same turbulence values from hydrodynamic circulation models (Werner et al. 1996, 2001), and prey fields (concentrations, distributions, size-structure, total dry weight: $\sim 20 \mu \mathrm{g}$ dry weight $\mathrm{l}^{-1}$ ) as those used by Werner et al. $(1996,2001)$ for the Southern Flank of Georges Bank to facilitate comparisons with earlier model results. The prey field and concentration is the same at all locations and depths. Simulations with $6 \mathrm{~mm}$ (Fig. 7a) and $10 \mathrm{~mm}$ (Fig. 7b) larvae are presented.

Predictions from our model deviate considerably from previous simulations of larval cod on Georges Bank. First, the most obvious difference is the reduction in feeding rates with increasing depth in our model. Earlier models have assumed that the reactive distance is a fixed fraction of body length, and thus that feeding rates are unaffected by the reduction in light with depth. Second, our model predicts higher ingestion rates, and apparently, the larvae are not food limited in the upper $50 \mathrm{~m}$ under the model conditions. Although we have not included bioenergetic models here, studies such as Kiørboe et al. (1987) indicate that growth of herring larvae becomes temperature limited at daily ingestion rates near 20 to $30 \%$ of body mass. 

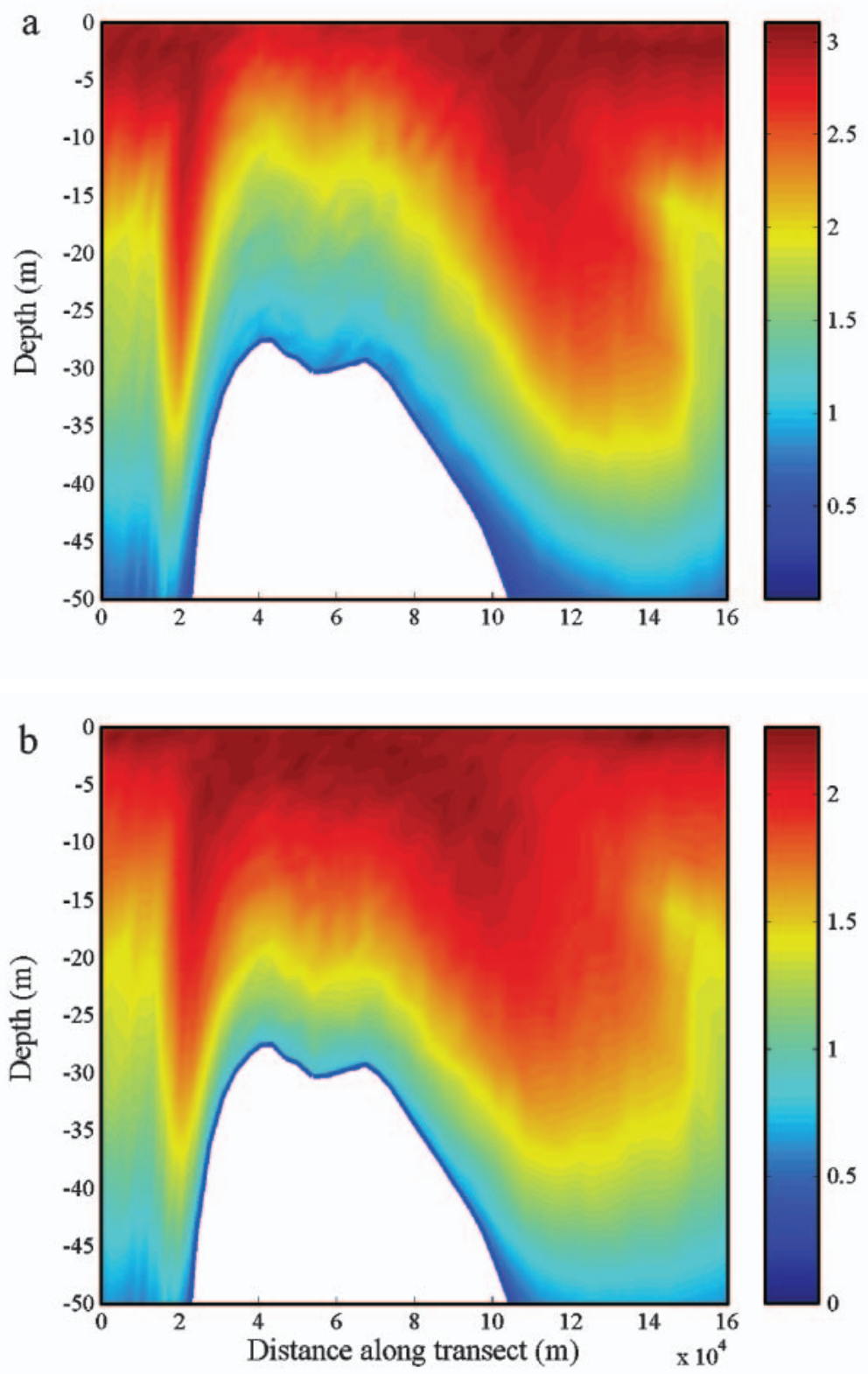

Fig. 7. Diel specific ingestion rates (total weight of prey ingested [larval body weight $]^{-1} \mathrm{~d}^{-1}$ ) of fish larvae at various depths across a section of Georges Bank. The diel variability in spatial and temporal environmental forcing includes light and turbulence generated by the tidal cycle and climatological wind at surface. The maximal surface irradiance at mid-day was $500 \mu \mathrm{mol} \mathrm{m} \mathrm{m}^{-2} \mathrm{~s}^{-1}$, and followed the natural diel periodicity for Georges Bank in early April. Light attenuates exponentially, assuming a light extinction coefficient of $0.12 \mathrm{~m}^{-1}$. (a) $6 \mathrm{~mm}$ larvae. (b) $10 \mathrm{~mm}$ larvae. Note the difference in scale between the panels

Larval cod grow 10 to $15 \% \mathrm{~d}^{-1}$ when reared at $8^{\circ} \mathrm{C}$ and high food ration (Otterlei et al. 1999). Therefore, an ingestion rate near 1 body mass $\mathrm{d}^{-1}$ should enable them to grow at maximum rates. Third, the decay of light with depth has implications for the effects of tur- bulence on feeding. Werner et al. (1996) found feeding rates to be maximised near the bottom, where the tide generates strong turbulence, but this was modified when the downside of turbulence was included in the model (Werner et al. 2001). Turbulence in deep waters is even more detrimental to feeding success when the decay of light (and visual range) is included, as in our model. This can be seen in Fig. 7, where high feeding rates are found deeper into the water column over the deeper and more stratified areas of the bank, where turbulence levels are intermediate.

The optimal location both horizontally and vertically (in terms of ingestion rate) depends on larval size (Fig. 7). Larger larvae have more sensitive eyes, longer reactive distance and are less susceptible to the downside of turbulence. Consequently, the enhanced level of turbulence on the shallow, well-mixed areas of the bank is beneficial to larger larvae, but detrimental to smaller larvae (Fig. 7). Thus, for the given prey field, smaller larvae obtain their highest ingestion rates at the fringes of the bank, while larger larvae have maximum feeding rates near surface at the centre of the bank. If turbidity is higher than the extinction coefficient used in Fig. $7\left(0.12 \mathrm{~m}^{-1}\right)$, food limitation will be more important, partly due to shorter reactive distance and partly due to more loss of prey from turbulence. However, in near surface waters, we would not expect to see food-limited larvae under the conditions specified here. Note also that the deeper habitats or more turbidity could be profitable if the predation pressure from visually searching planktivores (fish) is substantial, since these will be less efficient at reduced light levels (Fiksen et al. in press).

\section{DISCUSSION}

Our model is inspired by earlier models of encounter and capture processes. First, Eggers (1977) and more explicitly, Aksnes \& Giske (1993) emphasised the importance of light on the prey encounter process in planktivorous fish. The reactive distance is non-linearly related to light; it levels off due to scattering and satiation in the visual apparatus of 
the fish (Aksnes \& Utne 1997). All models of fish feeding are highly sensitive to parameterisation of visual range, and more experimental studies should be directed into estimating the effects of light and aspects of prey on visual range.

Second, our model of larval approach success is adopted from Caparroy et al. (2000), but we applied estimates of actual pursuit times and strike distance. Pursuit duration is a behavioural trait that cannot be modelled mechanistically. The alternatives are to assimilate data into the model or to assume some sort of flexibility in this trait. For instance, we could easily modify the model to the situation where the approach velocity is constrained to be below the velocity generating deformation rates above the sensitivity threshold of the prey, such that $P_{\mathrm{sa}}$ is always 1 . This prudent predator always adjusts the approach velocity to the sensitivity of its prey. Another alternative could be to include the random jump frequency of prey in the approach success. Copepods may jump from several times per second to only a few times per minute (Titelman 2001), and this behaviour may be relevant to the time fish can spend on approaching a prey. However, at least for larval cod, the results appear not to be very sensitive to these assumptions. Larval cod approach their prey slowly enough not to exceed the sensitivity threshold of their prey (Fig. 3, Table 1), and at least in theory, rarely elicit a prey escape response before attack.

Recent investigations (reviewed in Visser 2001) have also found that zooplankton habituate to high levels of turbulence by increasing their threshold sensitivity for escape jumps. This would allow larvae to approach even faster or closer to the prey before striking at higher turbulence levels. Similarly, the tendencies of increased jump frequency (Saiz \& Alcaraz 1992) and decreased reaction distance (Saiz \& Kiørboe 1995) of copepods with turbulence probably contribute to enhance larval feeding success at higher turbulence levels, but this is not included in the model.

Capture success and consequently strike distance is more critical for feeding success (Fig. 3). Again, strike distance is also a behavioural feature, and we presented the sensitivity of this parameter on feeding success in Fig. 5. The model suggests that strike distance is not an important parameter in small ( $3 \%$ of body length) prey, but for large prey ( $7 \%$ of body length), the larvae should be closer and more careful to be at the right distance before the final attack. The calculations of capture success are a simplification of the model by Caparroy et al. (2000). We have adapted it specifically to fish as predators, and applied explicit parameters of mouth size and prey escape directions.
Thirdly, the 'downside of turbulence' has been placed in a mechanistic context along with the classical encounter, pursuit, attack and capture/retention predation cycle. Our model represents a major simplification of the original model in MacKenzie et al. (1994), but the predictions remain similar and fall nicely within the observed data from MacKenzie \& Kiørboe (2000). We emphasise the benefit of our expressions in terms of computer time; this model is much faster to solve than previous versions. The rest of the processes are also ideal for implementation in large individualbased models; they are stochastic and rapid to execute. The most time-consuming process in terms of computation is approach success, but this may be further simplified (e.g. by assuming that approach velocity is always less than the critical velocity eliciting prey escape) without significant loss of precision.

All of the model components, except maybe the approach success, are needed to make inferences on prey selection. For some time, discussions on the relative importance of purely physical processes and more biological, adaptive processes (optimal foraging) on the diet of planktivorous fish has flourished in the literature (O'Brien et al 1976, Li et al. 1985). Studies comparing observed diets with modelled diets suggested that prey selection in fish could be explained by the 'apparent size' or 'reactive field volume' models (Wright \& O'Brien 1984, Li et al. 1985). Luo et al. (1996) found the same in their spatially explicit model of prey selection. Others have found some sort of inherent prey selection more likely (e.g. Gardener 1981, Eggers 1982). We found that the diet in larval cod and herring was well explained by the prey encounter rate and capture success, i.e. by the 'reactive field model', rather than prey selection. Our model assumes that all prey is encountered sequentially, at rates determined by Eq. (1), and that all encountered prey is attacked. Strictly, this would only be valid under food-limiting conditions, and not for the situation which is depicted by the apparent size model, where several prey may be encountered at once, and a selection among them has to be made (Eggers 1977). However, before the tools for treating trade-offs between growth and mortality within the same framework was developed (Houston et al. 1988), optimal foraging theory was more biased towards maximising energetic gain than minimising predation risk. Along this line of reasoning, Giske \& Salvanes (1995) argued that planktivores should be unselective feeders. If both growth and mortality increase with any specific behaviour, such as swimming speed or depth, then a planktivore should adjust its behaviour such that it never becomes over-satiated or digestionlimited (Giske \& Salvanes 1995). That is, if a fish larva is filling its stomach, it should sink deeper and reduce 
its activity level to reduce predation risk from other fish, instead of benefitting from the luxury of selecting among particular prey items.

In fact, cod larvae reduced their search activity at high prey densities in experimental tanks (MacKenzie \& Kiørboe 1995, Munk 1995). The model does not allow the larvae to adjust their search rates with prey density, and the relation between clearance and encounter is constant. Consequently, the model can not replicate the results from Munk (1995) and MacKenzie \& Kiørboe (1995) at both high and low prey densities with the fixed search velocity defined by $f$ and $\lambda$ in Eq. (1). However, overestimating the encounter rate at high prey concentrations will not affect the growth rate due to satiation, while the feeding success at low food availability is crucial for growth and survival. Therefore, the model is potentially most useful for evaluating feeding rates at low prey concentrations, and this is where it corresponds well to the data. Again, if larval fish behave as adaptive foragers, they should not reach complete satiation as long as foraging also incurs risk of predation (McNamara \& Houston 1987, Giske \& Salvanes 1995).

In our simulations, we could not find any trends in prey size selection (Chesson's index) for various light or turbulence levels. The capture success is more important than approach or pursuit success in determining the drop in ingestion rate with increasing prey size (Fig. 3). Likewise, the increase in reactive distance from larger prey image area is the most important factor in the 'upside'. Field studies have revealed ambiguous patterns of size-selectivity with turbulence, suggesting both larger (Dower et al. 1998) and smaller (Hillgruber \& Kloppmann 2000) prey to be selected at higher turbulence.

We calculated the prey size selectivity of larvae that differed only in respect of search mode, i.e. cruising or pause-travel. The difference emerges because pause-travel predators scan a more spherical search volume. However, we know of no general observations on the relative prey-size selectivity between pause-travel and cruising fish, and the morphological differences between species, e.g. lengthand mouth-size differences between cod and herring larvae, would mask such effects. The ability of the model to predict the preferred prey size range of both herring and cod larvae by simply switching search mode and mouth size is encouraging, and exemplifies the generality implicit in mechanistic models.

The model includes the sensory ability of the prey in detecting the approaching larvae. In summary, cod larvae appear to approach at velocities slow enough not to elicit an escape response from the prey. However, this constrains the ability of the larva to com- pensate the increasing loss of prey from view at higher turbulence by reducing the pursuit time. MacKenzie \& Kiørboe (2000) found decreasing pursuit times of larval cod at increasing turbulence levels. One potential explanation of this finding is that more pursuit sequences are aborted, and therefore the pursuit time appears shorter. Although we cannot rule out this alternative hypothesis, the model suggests that reducing pursuit times with increasing turbulence levels is profitable in terms of overall ingestion rate, as the benefits of this behaviour (increased pursuit successes) outweigh the costs (lower approach successes).

Processes affecting recruitment of cod on Georges Bank have received much attention over the last decade. In particular, a number of model-based studies have explored the association between physical variables such as large-scale circulation and smallscale turbulence and biological variables such as prey abundance and larval physiology (Werner et al. 1996, 2001, Lynch et al. 2001). Our model differs from these both on the general level of food limitation and the spatial assessment of growth conditions. We have not included aspects other than ingestion rate, such as metabolic costs and stomach limitation. However, the high ingestion rates predicted by the model across the bank (Fig. 7) suggest that food limitation is unlikely at these prey concentrations. The ability of the model to explain feeding rates under natural conditions in both cod and other species should be further investigated to assess the generality and validity of the model.

Understanding of the full impacts of turbulence on the ecology of zoo- and ichthyoplankton is growing but major gaps remain. In this investigation we have attempted to increase the biological realism of larval fish feeding models. This effort appears to have been successful given the reasonable consistency of the new model with previous field and laboratory results. The model is also numerically simple and requires little computational resources. This should facilitate inclusion of these processes in more complex models of plankton production, larval fish ecology and pelagic ecosystem functioning, as illustrated in our example of larval cod at Georges Bank.

Acknowledgements. We thank Dag L. Aksnes, Jarl Giske, Thomas Kiørboe and Peter Munk for comments on an earlier version of the manuscript, and Andy Visser for discussions during the model development. F. E. Werner kindly provided us with energy dissipation rates from simulations across Georges Bank. This work was carried out during a postdoctoral visit by $\varnothing . F$. to B.R.M. at DFU in Copenhagen, funded by the research council of Norway (NRC) (133562/120). Additional support to B.R.M. was provided by the European Union (FAIR contract CT-98-3959). 


\section{LITERATURE CITED}

Aksnes DL, Giske J (1993) A theoretical model of aquatic visual feeding. Ecol Mod 67:233-250

Aksnes DL, Utne ACW (1997) A revised model of the visual range in fish. Sarsia 82:137-147

Bailey KM, Batty RS (1984) Laboratory study of predation by Aurelia aurita on larvae of cod, flounder, plaice and herring: development and vulnerability to capture. Mar Biol 83:287-291

Blaxter JHS (1986) Development of sense organs and behaviour of teleost larvae with special reference to feeding and predator avoidance. Trans Am Fish Soc 115:98-114

Buskey EJ (1994) Factors affecting feeding selectivity of visual predators on the copepod Acartia tonsa: locomotion, visibility and escape processes. Hydrobiologia 292/293: $447-453$

Buskey EJ, Coulter C, Strom SL (1993) Locomotory patterns of microzooplankton: potential effects on food selectivity of larval fish. Bull Mar Sci 53:29-43

Dower JF, Pepin P, Leggett WC (1998) Enhanced gut fullness and an apparent shift in size selectivity by radiated shanny (Ulvaria subbifurcata) larvae in response to increased turbulence. Can J Fish Aquat Sci 55:128-142

Caparroy P, Thygesen UH, Visser AW (2000) Modelling the attack success of planktonic predators: patterns and mechanisms of prey size selectivity. J Plankton Res 22: $1871-1900$

Drost MR (1987) Relation between aiming and catch success in larval fishes. Can J Fish Aquat Sci 44:304-315

Eggers DM (1977) The nature of prey selection by planktivorous fish. Ecology 58:46-59

Eggers DM (1982) Planktivore preference by prey size. Ecology 63:381-390

Ellertsen B, Solemdal P, Strømme T, Tilseth S, Westgård T, Moksness E, Øiestad V (1980) Some biological aspects of cod larvae (Gadus morhua L). Fisk Dir Ser Hav Unders 17:29-47

Fiksen Ø, Folkvord A (1999) Modelling growth and ingestion processes in herring larvae (Clupea harengus L). Mar Ecol Prog Ser 184:273-289

Fiksen Ø, Utne ACW, Aksnes DL, Eiane K, Helvik JV, Sundby S (1998) Modelling the influence of light, turbulence and development on foraging in larval cod and herring. Fish Oceanogr 7:354-363

Fiksen $\varnothing$, Aksnes DL, Flyum MH, Giske J (in press) The influence of turbidity on growth and survival of fish larvae-a numerical analysis. Hydrobiologia

Gardener MB (1981) Mechanisms of size selectivity by planktivorous fish: a test of hypotheses. Ecology 62:571-578

Giske J, Salvanes AGV (1995) Why pelagic planktivores should be unselective feeders. J Theor Biol 173:41-50

Heath MR (1993) The role of escape reactions in determining the size distribution of prey captured by herring larvae. Environ Biol Fish 38:331-344

Hillgruber N, Kloppmann M (2000) Vertical distribution and feeding of larval blue whiting in turbulent waters above Porcupine Bank. J Fish Biol 57:1290-1311

Hinckley S, Hermann AJ, Megrey BA (1996) Development of a spatially explicit, individual-based model of marine fish early life history. Mar Ecol Prog Ser 139:47-68

Houston AI, Clark CW, McNamara J, Mangel M (1988) Dynamic models in behavioural and evolutionary ecology. Nature 332:29-34

Hunter JR (1972) Swimming and feeding behaviour of larval anchovy, Engraulis mordax. Fish Bull 70:821-838

Hunt von Herbing I, Gallager SM (2000) Foraging behavior in early Atlantic cod larvae (Gadus morhua) feeding on a protozooan (Balanion sp.) and a copepod nauplius (Pseudodiaptomus sp.). Mar Biol 136:591-602

Hunt von Herbing I, Gallager SM, Halteman W (2001) Metabolic costs of pursuit and attack in early larval Atlantic cod. Mar Ecol Prog Ser 216:201-212

Huse I (1994) Feeding at different illumination levels in larvae of 3 marine teleost species: cod, Gadus morhua L., plaice, Pleuronectes platessa L., and turbot, Scophthalmus maximus (L.). Aqua Fish Man 25:687-695

Job SD, Bellwood DR (2000) Light sensitivity in larval fishes: implications for vertical zonation in the pelagic zone. Limnol Oceanogr 45:362-371

Kiørboe T, Saiz E (1995) Planktivorous feeding in calm and turbulent environments with emphasis on copepods. Mar Ecol Prog Ser 122:135-145

Kiørboe T, Visser A (1999) Predator and prey perception in copepods due to hydromechanical signals. Mar Ecol Prog Ser 179:81-95

Kiørboe T, Munk P, Richardson K (1987) Respiration and growth of larval herring Clupea harengus: relation between specific dynamic action and growth efficiency. Mar Ecol Prog Ser 40:1-10

Kiørboe T, Saiz E, Visser A (1999) Hydrodynamic signal perception in the copepod Acartia tonsa. Mar Ecol Prog Ser 179:97-111

Leising AW, Franks PJS (1999) Larval Atlantic cod (Gadus morhua) and haddock (Melanogramma aeglefinus) growth on Georges Bank: a model with temperature, prey size and turbulence forcing. Can J Fish Aquat Sci 56:25-36

Li KT, Wetterer JK, Hairston NG Jr (1985) Fish size, visual resolution, and prey selectivity. Ecology 66:1729-1735

Lou J, Brandt SB, Klebasko MJ (1996) Virtual reality of planktivores: a fish's perspective of prey size selection. Mar Ecol Prog Ser 140:271-283

Lynch DR, Lewis CVW, Werner FE (2001) Can Georges Bank larval cod survive on a calanoid diet? Deep-Sea Res II 48:609-630

MacKenzie BR, Kiørboe T (1995) Encounter rates and swimming behaviour of pause travel and cruise larval fish predators in calm and turbulent environments. Limnol Oceanogr 40:1278-1289

MacKenzie BR, Kiørboe T (2000) Larval fish feeding and turbulence: a case for the downside. Limnol Oceanogr 45: $1-10$

MacKenzie BR, Miller TJ, Cyr S, Leggett WC (1994) Evidence for a dome-shaped relationship between turbulence and larval fish ingestion rate. Limnol Oceanogr 39:1790-1799

McNamara JM, Houston AI (1987) Starvation and predation as factors limiting population size. Ecology 68:1515-1519

Mauchline M (1998) The biology of calanoid copepods. Adv Mar Biol 33:1-710

Munk P (1992) Foraging behaviour and prey size spectra of larval herring Clupea harengus. Mar Ecol Prog Ser 80: $149-158$

Munk P (1995) Foraging behaviour of larval cod (Gadus morhua) influenced by prey density and hunger. Mar Biol 122:205-212

Munk P (1997) Prey size spectra and prey availability of larval and small juvenile cod. J Fish Biol 51(Suppl A):340-351

O'Brien WJ (1987) Planktivory by freshwater fish: thrust and parry in the pelagia. In: Kerfoot WC, Sih A (eds) Predation: direct and indirect impacts on aquatic communities. University Press of New England, London, p 3-16

O'Brien WJ, Slade NA, Vinyard GL (1976) Apparent size as the determinant of prey selection by bluegill sunfish. Ecology 57:1304-1310

Otterlei E, Nyhammer G, Folkvord A, Stefansson SO (1999) 
Temperature- and size-dependent growth of larval and early juvenile Atlantic cod (Gadus morhua): a comparative study of Norwegian coastal cod and northeast Arctic cod. Can J Fish Aquat Sci 56:2099-2111

Puvanendran V, Brown JA (1998) Effect of light intensity on the foraging and growth of Atlantic cod larvae: interpopulation difference? Mar Ecol Prog Ser 167:207-214

Rasmussen J (1999) Predator-prey interactions for larval cod (Gadus morhua) and copepods (Acartia tonsa) in calm and turbulent water. Master's thesis, University of Århus

Rothschild BJ, Osborn TR (1988) Small-scale turbulence and plankton contact rates. J Plankton Res 10:465-474

Saiz E, Alcaraz M (1992) Free-swimming behaviour of Acartia clausi (Copepoda:Calanoida) under turbulent water movement. Mar Ecol Prog Ser 80:229-236

Saiz E, Kiørboe T (1995) Predatory and suspension feeding of the copepod Acartia tonsa in turbulent environments. Mar Ecol Prog Ser 122:147-158

Titelman J (2001) Swimming and escape behaviour of copepod nauplii: implications for predator-prey interactions among copepods. Mar Ecol Prog Ser 213:203-213

Utne-Palm AC (1999) The effect of prey mobility, prey contrast, turbidity and spectral composition on the reaction distance of Gobiusculus flavescens to its planktonic prey. J Fish Biol 54:1244-1258

Editorial responsibility: Otto Kinne (Editor),

Oldendorf/Luhe, Germany van der Meeren T, Jørstad KE (2001) Growth and survival of Arcto-Norwegian and Norwegian coastal cod larvae (Gadus morhua L.) reared together in mesocosms under different light regimes. Aquacult Res 32:549-563

Viitasalo M, Kiørboe T, Flinkman J, Pedersen LW, Visser AW (1998) Predation vulnerability of planktonic copepods: consequences of predator foraging strategies and prey sensory abilities. Mar Ecol Prog Ser 175:129-142

Viitasalo M, Flinkman J, Viherluoto M (2001) Zooplanktivory in the Baltic Sea: a comparison of prey selectivity by Clupea harengus and Mysis mixta, with reference to prey escape reactions. Mar Ecol Prog Ser 216:191-200

Visser AW (2001) Hydromechanical signals in the plankton. Mar Ecol Prog Ser 222:1-24

Werner FE, Perry RI, Lough RG, Naimie CE (1996) Trophodynamic and advective influences on Georges Bank larval cod and haddock. Deep-Sea Res Part II 43: 1793-1822

Werner FE, MacKenzie BR, Perry RI, Lough RG, Naimie CE, Blanton BO, Quinlan JA (2001) Larval trophodynamics, turbulence, and drift on Georges Bank: a sensitivity analysis of cod and haddock. Sci Mar 65:99-115

Wright DI, O'Brien WJ (1984) The development and field test of a tactical model of the planktivorous feeding of white crappie (Pomoxis annularis). Ecol Monogr 54:65-98

Submitted: April 10, 2002; Accepted: August 6, 2002

Proofs received from author(s): November 1, 2002 